\title{
MULTIPLICANDO AS CIÊNCIAS: UM ESTUDO ETNOGRÁFICO SOBRE FAZERES CIENTÍFICOS DA EDUCAÇÃO FÍSICA
}

\author{
MULTIPLYING SCIENCES: ETHNOGRAPHIC STUDIES ABOUT SCIENTIFIC \\ WORK IN PHYSICAL EDUCATION
}

\author{
MULTIPLICANDO LAS CIENCIAS: ESTUDIO ETNOGRÁFICO SOBRE LOS \\ HACERES CIENTÍFICOS DE LA EDUCACIÓN FÍSICA
}

\author{
Raquel da Silveira*, Marco Paulo Stigger*, Mauro Myskiw*
}

\begin{abstract}
Palavras chave:
Educação Física.

Ciência.

Antropologia

Cultural.

Conhecimento.

Resumo: Desde os anos 2000 ocorreram ampliações e intensificações da comunidade de pesquisadores(as) e dos aparatos científicos comprometidos com a Educação Física (EF). Esse processo aconteceu/acontece em meio a diversos tensionamentos que passaram a ser problematizados em estudos e debates. Instigados por esses fatos e problematizações, o objetivo desta pesquisa é compreender de que modo se faz ciência na EF brasileira. Para isso realizamos um estudo etnográfico em dois grupos de pesquisa da $E F$, em que seguimos humanos e não humanos, associações e controvérsias. Ao acompanhar o dia a dia desses grupos chegamos à conclusão de que há múltiplas ciências da EF. Diante dessa constatação, o principal encaminhamento e provocação desta pesquisa é que ao indagar sobre a ciência da EF (note-se, no singular) passa a ser indispensável indagar sobre os tipos de relações que foram e estão sendo estabelecidas entre as ciências da EF (note-se, múltiplas), e quais são as suas consequências.
\end{abstract}

Keywords:

Physical Education.

Science.

Anthropology,

Cultural.

Knowledge.

Palabras clave: Educación Física.

Ciencia.

Antropología

Cultural.

Conocimiento.
Abstract: Since the 2000s, the research community and scientific apparatuses engaged with Physical Education (PE) have widened and intensified. Such process has happened and still happens amid several tensions that began to be discussed in studies and debates. Driven by these facts and questionings, this research looks into how science is done in Brazilian PE. An ethnographic study has been conducted within two PE research groups, where we followed humans and non-humans, associations and controversies. After following the everyday work of these groups, we found that there are multiple PE sciences. In view of these findings, the main conclusion and provocation of this study is that, to question PE science - in singular form - it is crucial to ask about the types of relations that have been established and still remain among PE sciences - in plural - and their consequences.

Resumen: Desde los años 2000 ocurrieron ampliaciones e intensificaciones de la comunidad de investigadores/as y de los aparatos científicos involucrados con la Educación Física (EF). Este proceso ocurrió y ocurre en medio a distintas tensiones que pasaron a ser problematizadas en estudios y debates. Motivados por estos hechos y problematizaciones, el objetivo de esta investigación es comprender de qué modo se hace ciencia en la EF brasileña. Con este fin, realizamos un estudio etnográfico en dos grupos de investigación de la EF, donde seguimos humanos y no humanos, asociaciones y controversias. Al acompañar la jornada de estos grupos, llegamos a la conclusión de que hay múltiples ciencias de la EF. Frente a esta constatación, el principal encaminamiento, y la provocación de esta investigación, es que, al indagar sobre la ciencia de la EF (destaque para el singular) se vuelve indispensable indagar sobre los tipos de relaciones que han sido establecidas y se establecen entre las ciencias de la EF (múltiples) y cuáles son sus consecuencias.
*Universidade Federal do Rio Grande do Sul (UFRGS). Porto Alegre, RS, Brasil.

E-mail: raqufrgs@gmail.com; stigger.mp@gmail.com; mmyskiw@ hotmail.com

Recebido em: 08-05-2018 Aprovado em: 16-03-2019 Publicado em: 23-04-2019

DOI: https://doi.org/10.22456/1982-8918.82693 (c) (1) (8) Licence 


\section{INTRODUÇÃO}

A produção de conhecimento científico no Brasil data do início do século XIX, mas é a partir de 1975, através de consecutivos Planos Nacionais de Pós-Graduação, que se inicia uma política indutiva do Estado brasileiro voltada para a formação de pesquisadores(as) e de incentivo à pesquisa (STIGGER; SILVEIRA; MYSKIW, 2015). Esse processo de indução reverberou nas políticas da Educação Física (EF) brasileira, fazendo com que muitos programas de pós-graduação (PPG) fossem criados a partir desse momento1. Lazzarotti Filho (2011) acrescenta a essa ideia o marco dos anos 2000 como o momento em que, no Brasil, "[...] o campo se amplia, se dinamiza e incorpora as práticas científicas com mais intensidade, trazendo consigo todo o seu aparato, colocando-as na disputa do poder de visão e de divisão do campo" (p. 111). É nesse período que há uma "[...] incorporação definitiva e definidora das práticas científicas trazendo para a Educação Física novas conformações" (2011, p. 111 e 112).

Estudos recentes sobre ciência e $\mathrm{EF}^{2}$ direcionaram suas preocupações para a produção de conhecimento lançando luz às inúmeras regras, instituições, agentes, aspectos financeiros e sistemas de avaliação que tal produção requer na esfera atual. Essas são as agendas que hoje ganham destaque, sendo os cursos de pós-graduação, os periódicos científicos e 0 sistema de avaliação regido pela Capes os principais espaços em que essas pautas foram/são problematizadas. Nesses estudos, chama a atenção uma característica marcante da produção de conhecimento em EF: sua separação em, ao menos, duas áreas/subáreas. Há, por um lado, pesquisas que se vinculam às "ciências duras", "Ciências Biológicas", "Ciência Biológicas e da Saúde", "Ciências Biodinâmicas", e há por outro lado, pesquisas vinculadas às "ciências moles", "Ciências Sociais", "Ciências Pedagógicas", "Ciências Humanas e Sociais", "Ciências Socioculturais", "Ciências Socioculturais e Pedagógicas". Essas diversas denominações materializam a divisão que parece reger a compreensão atual sobre a maneira com que se faz ciência na $\mathrm{EF}^{3}$.

As implicações dessa divisão são diversas. Conforme identificaram Manoel e Carvalho (2011), a Biodinâmica tem hegemonia no campo. Seja em relação à característica da pósgraduação brasileira (MANOEL; CARVALHO, 2011 e TAVARES, 2015), seja em relação às formas e veículos de produção científica (LAZZAROTTI FILHO et al., 2012), ficam evidentes as discrepâncias das áreas/subáreas da EF e a valorização das Ciências Biológicas e da Saúde. Rigo, Ribeiro e Hallal (2011) e Marchlewski, Silva e Soriano (2011) investigaram as implicações dessa divisão no sistema de avaliação dos periódicos em que a produção da EF está sendo alocada: o Qualis - sistema de classificação de periódicos regido pela Capes. Ambos os estudos apontam uma valorização dos conhecimentos produzidos na área das Ciências Biológicas e da Saúde devido, principalmente, a três aspectos: a supervalorização dos periódicos internacionais; a não valorização dos periódicos editorados em áreas

\footnotetext{
1 A Universidade de São Paulo criou, em 1977, o primeiro mestrado em EF da América Latina. Depois, a Universidade Federal de Santa Maria, em 1979, e a Universidade Federal do Rio de Janeiro, em 1980, criaram cursos de mestrado em EF (SILVA, 1997). Mas a expansão dos PPGs aconteceu a partir de 1990, quando se contabilizavam sete cursos de mestrado e um de doutorado em EF (RIGO; RIBEIRO; HALLAL, 2011) sendo que em 2012 esses números já somavam 52 cursos.

2 Ver: Stigger et al. (2010); Lazzarotti Filho (2011); Manoel e Carvalho (2011); e duas coletâneas organizadas por Rechia et al. (2015) e Stigger (2015).

3 Em que pesem as suas particularidades, é dessa forma que são encontradas essas diferentes denominações que circulam nesse universo acadêmico. Ver em: Rigo, Ribeiro e Hallal, 2011; Marchlewski, Silva e Soriano, 2011; Lazzarotti Filho, 2011; Lazzarotti Filho et al., 2012; 
"madrinhas"4 das Ciências Humanas e Sociais; e a superioridade quantitativa de periódicos com escopo voltado para as áreas biológicas e da saúde classificados nos estratos superiores, se comparados aos vinculados às áreas humanas e sociais. Frente a esse panorama, uma das principais consequências apontadas em alguns estudos é o "movimento migratório" (RIGO; RIBEIRO; HALLAL, 2011, p. 344) dos(as) pesquisadores(as) das áreas humanas e sociais para outros PPGs não vinculados à Área 21 da Capes.

Dessa forma, ao se problematizar a divisão entre Ciências Humanas e Sociais e Ciências Biológicas e da Saúde, que parecem constituir a ciência da EF, é possível constatar que essa divisão provoca tensões e disputas entre os(as) pesquisadores(as) da EF. Os estudos mencionados mostram que é um campo - conforme a noção bourdieusiana de que a maioria dos estudos parecem compartilhar (com mais ou menos afinco) - que está sendo mantido com base em diversos tipos de conflitos e resistências. Nesse sentido, fica compreensível que as principais motivações que nos provocaram a realizar esta pesquisa estão relacionadas às tensões, conflitos, disputas, discrepâncias, desigualdades e resistências que vivenciamos na condição de participantes da constituição e manutenção desse campo científico, especificamente participante e comprometidos com as áreas socioculturais.

Assim como nos estudos mencionados, nosso ponto de partida foi a compreensão de um campo científico que se apresentava dividido em áreas/subáreas, em que tensões, disputas, desigualdades e resistências eram características centrais. Contudo, conforme nos apropriávamos dos debates, informações, dados, análises e reflexões que estavam presentes nesses estudos, passamos a questionar sobre esse ponto de partida, pois ele parecia minimizar as possibilidades de compreensão sobre o modo com que a ciência da EF acontecia no cotidiano. Algumas perguntas nos pareciam pertinentes de serem respondidas sobre ele: o que caracteriza as áreas/subáreas que dividem a ciência da EF? Quais fronteiras estão sustentando cada uma dessas instâncias? De que maneira no dia a dia da produção do conhecimento essas divisões se apresentam? Assim, a partir da aproximação com os chamados Estudos Sociais da Ciência e Tecnologia (ESCT), nossas inquietações se voltaram para os fazeres científicos, para elementos humanos e não humanos ${ }^{5}$ que diariamente protagonizavam planejamentos, produções e publicações de pesquisas e conhecimentos que, em algum momento desse percurso, tornavam-se áreas/subáreas, com delimitações quase inquestionáveis. Nesse sentido, optamos por modificar o ponto de partida e questionar: de que modo se faz ciência na Educação Física brasileira, quando nos voltamos para o cotidiano de seus grupos/ laboratórios, humanos e não humanos?

\section{MULTIPLICANDO A REALIDADE: FERRAMENTAS TEÓRICO-METODOLÓGICO- ANALÍTICAS PARA COMPREENDER A(S) CIÊNCIA(S) DA EDUCAÇÃO FÍSICA}

[...] olhar para a multiplicidade da realidade também é um ato. É algo que se pode fazer - ou deixar de fazer. É uma intervenção. Ele intervém nos vários estilos disponíveis para descrever práticas (MOL, 2002, p. 6).

\footnotetext{
4 Termo utilizado por Rigo, Ribeiro e Hallal (2011) para fazer referência às diferentes áreas que dialogam com as Ciências Humanas e Sociais (por exemplo, Educação, História, Filosofia, Sociologia etc.).

50 par "humano e não humano" faz parte do vocabulário que os Estudos Sociais da Ciência e Tecnologia cunharam para expressar possibilidades de relação e ação entre seres humanos e objetos, animais, tecnologias etc. Ao colocarem em suspensão as dicotomias da modernidade, em especial entre cultura e natureza, os ESCT optam por não utilizar a tradicional distinção entre sujeito/objeto (em que o primeiro é o que tem o poder da ação e o segundo o que recebe a ação) e passam a utilizar as noções de humano e não humano para referir-se a todo e qualquer elemento que pode constituir e possuir a capacidade de modificar alguma ação em determinada ciência, ou fazer científico.
} 
De maneira ampla, consideramos que a multiplicidade da realidade - forma com que passamos a nos relacionar com a temática da ciência e EF-é um desdobramento da interlocução que estabelecemos com os denominados ESCT. Sucintamente, é possível caracterizar os ESCT como um "campo multidisciplinar" (HAYASHI et al., 2010, p. 78), que surgiu na década de 1970, formado por pesquisadores(as) que se dedicaram a compreender as ciências a partir de alguns preceitos em comum, por exemplo, pressupor que "[...] o conhecimento científico não é mais analisado como o produto de um processo cognitivo privilegiado. Ele passa a ser considerado o resultado de práticas sociais" (HAYASHI et al., 2010, p. 77). Os ESCT propõem ampliar as possibilidades de se compreender as ciências, os cientistas, os fatos científicos, as instituições que as financiam, as avaliam e as regem.

Nos estudos de Latour (2001) e de Law (1992), destaca-se a diversidade de redes científicas descritas que mostram diferentes realidades de ciências. Eles apontam para a multiplicidade de ciências que são, na prática, diariamente criadas, mantidas e/ou alteradas. Esses autores nos ofertaram um conjunto de ferramentas teórico-analíticas que nos direcionaram a seguir elementos, ver associações e desfazer um entendimento único - ou binário - sobre as realidades científicas que investigamos.

Para Latour "a única maneira de compreender a realidade dos estudos científicos é acompanhar o que eles [cientistas] fazem de melhor, ou seja, prestar atenção aos detalhes da prática científica" (LATOUR, 2001, p. 39). Assim, realizamos uma etnografia em dois grupos de pesquisa vinculados à mesma escola de ensino superior de EF em uma universidade pública e ao mesmo PPG em EF localizados na Região Sul do país ${ }^{6}$. Para a escolha desses grupos, que aconteceu no início da pesquisa, nos pautamos na produção científica em voga sobre o tema, conforme anunciamos na Introdução. Nessa produção o entendimento de campo científico atribuído à ciência da EF, o qual pressupõe uma divisão em, ao menos, duas áreas/subáreas, se apresentava pertinente de ser contemplado. Assim, um dos grupos escolhidos - denominado ficticiamente de Vincennes - estava/está vinculado às Ciências Biológicas, e o outro grupo denominado ficticiamente de Buttes-Chaumont - estava/está vinculado às Ciências Humanas e Sociais ${ }^{7}$. O trabalho de campo durou, aproximadamente, 16 meses, período em que pudemos acompanhar o dia a dia desses dois grupos de pesquisa: permanecemos em suas salas e laboratórios; participamos de diversas reuniões; nos envolvemos e cooperamos com o planejamento, execução e publicação de algumas pesquisas; assistimos a diversas defesas de especialização, mestrado e doutorado; participamos e auxiliamos na organização de congressos científicos; estivemos presentes em momentos festivos; nos apropriamos das teses e dissertações que já haviam sido produzidas; e realizamos entrevistas com os pesquisadores e coordenadores de cada grupo.

Se, no início, nos preocupávamos em compreender os significados das ações dos(as) pesquisadores(as), tendo como referência as Ciências Humanas e Sociais e as Ciências Biológicas e da Saúde, com o andamento da pesquisa nossa atenção se voltou a identificar quais elementos (humanos e não humanos) e que tipos de associações estavam presentes nas ciências que cada grupo vivenciava. Com isso, passamos a seguir cientistas, temas de

6 Importante informar que o trabalho de campo etnográfico foi realizado pela primeira autora deste artigo. Optamos por manter a linguagem na primeira pessoa do plural para mantermos uma homogeneização na linguagem do texto.

7 Em diálogo com os respectivos grupos optou-se pelo anonimato dos seus nomes e dos(as) seus(uas) integrantes, logo, todos os nomes utilizados são fictícios. Compartilhar junto aos(às) cientistas que investigamos a decisão de utilizar ou não o anonimato foi uma ação embasada nas reflexões de Fonseca (2008), sobre suas próprias experiências de investigação. Ressaltamos que esta pesquisa foi aprovada no Comitê de Ética em Pesquisa da Universidade Federal do Rio Grande do Sul em 17 de maio de 2013 sob o Parecer de nº 275.118 . 
pesquisa e equipamentos. Nos diários de campo passamos a descrever redes que associavam elementos diversos e tinham a característica de serem feitas e desfeitas, além de limitadas em suas dimensões conforme a capacidade que tínhamos de observar, conhecer e compreender as ciências que investigávamos.

No processo analítico a noção de rede foi o alicerce para as análises das informações que elaborávamos ao longo do trabalho de campo. Foi a partir da compreensão da ciência enquanto um conjunto, sempre temporário, de associações de elementos diversos que visualizamos quem e o que integra os fazeres científicos dos grupos, as capacidades de agência dos diferentes elementos, a dinamicidade de algumas relações e os traçados deixados que ajudam a sustentar essas redes. Assim, foi com base no exercício de descrever que as análises presentes neste texto foram materializadas. Optamos por não escrever sobre as ciências, mas descrevê-las. Conforme nos ensina Mol (2002), é a partir da descrição da realidade que se pode compreender como algo que é considerado a priori, após as descrições mostra-se múltiplo. É trazendo ao texto as ações promulgadas na prática que se pode compreender as realidades que estão sendo criadas.

Além disso, os estudos de Mol (2002) nos encaminharam para uma continuidade/ desdobramento desse entendimento de ciência a partir da noção de ontologias múltiplas ${ }^{8}$ Essa noção, para além de nos remeter para uma compreensão de que a realidade é feita, vivenciada e promulgada nas práticas, também nos faz questionar as diferentes formas dessa multiplicidade de realidades coexistirem. A partir dessa autora, nos apropriamos de outro conjunto de ferramentas teórico-analíticas em que o percurso não acabou na ação de descrever múltiplas realidades científicas, mas nos provocou a continuar na direção de adentrar em suas diferentes maneiras de se relacionarem.

Foi no andamento da pesquisa, principalmente durante o trabalho de campo, que a noção de realidade múltipla se apresentou interessante e potente para compreender tamanha diferença de experiências que estávamos vivenciando em relação à ciência da $E F$. Os entendimentos que elaborávamos sobre os modos que se faz ciência na EF foram decorrências do contato - cada vez mais intenso - que estabelecíamos com as implicações da multiplicação da realidade. Compreendíamos que as respostas que elaborávamos eram parciais, transitórias e estavam sempre em aberto, pois, conforme os fazeres científicos da EF eram observados, percebíamos como eles eram produzidos e vivenciados, e como novas realidades estavam sendo sempre promulgadas. Com isso, construímos a compreensão de que existem e coexistem muitas outras ciências da EF além das duas que acompanhamos ao longo desta pesquisa. Umas com mais proximidades do que outras, com mais conexões do que outras, com mais entrelaçamentos do que outras.

Ao olhar para as ciências da EF, através do aporte teórico-metodológico dos ESCT, percebemos também que, diferentemente de um olhar que fragmenta uma única ciência da EF em áreas/subáreas - como até então compreendíamos -, não há características exclusivas e

8 A noção de ontologia presente nos estudos de Mol está em interlocução com o que ela denominou de "política ontológica" (MOL, 2008, p. 1). Ontologia, "que na linguagem filosófica comum define o que pertence ao real, às condições de possibilidades com que vivemos" (MOL, 2008, p. 2), autoriza diferentes maneiras de compreensão da realidade se for acompanhada e combinada com o termo "política". A composição desses dois termos abre possibilidades para se compreender que essas condições de possibilidades com que vivemos não são dadas, estáveis, fixas e determinadas. 0 acréscimo da política à realidade encaminha para o entendimento de que "a realidade não precede as práticas banais nas quais interagimos com ela, antes sendo modelada por essas práticas. 0 termo política, portanto, permite sublinhar este modo activo, este processo de modelação, bem como o seu carácter aberto e contestado" (MOL, 2008, p. 2). A realidade, nesse sentido, passa a ser produzida na prática. Referência Original: MOL, Annemarie. Ontological Politics. A word and some questions. In: LAW, John; HASSARD, John (org.) Actor Network Theory and After. Oxford: Blackwell, 1999. 
delimitações fixas entre as múltiplas ciências que são, na prática, criadas e mantidas. A diferença entre multiplicar e fragmentar foi se tornando cada vez mais evidente ao longo da pesquisa. Divisões quase que inquestionáveis (como, por exemplo, a fragmentação da ciência em naturais e sociais, e/ou da ciência da EF em biológicas e humanas) deixaram de ser as referências para aproximar ou afastar os fazeres científicos que acompanhávamos. A ação de descrever elementos e associações nos levou a perceber a multiplicidade de ciências que são vividas na prática ${ }^{9}$. Ao retornar para a epígrafe, "olhar para a multiplicidade da realidade" foi, na prática - e aqui nos referimos à nossa prática investigativa -, uma intervenção tanto no conjunto de entendimentos com que iniciamos esta pesquisa, quanto no fazer científico que desenvolvemos, e, consequentemente, nas descrições, análises e reflexões que aqui se materializam.

\section{VIVENDO CIÊNCIAS: DESCREVENDO ELEMENTOS E ASSOCIAÇÕES QUE PROMULGAM CIÊNCIAS DA EDUCAÇÃO FÍSICA}

Vincennes e Buttes-Chaumont são dois grupos de pesquisa que promulgam no seu dia a dia ciências da EF distintas, apesar de estarem lotadas na mesma instituição. Ambos os grupos agregam pesquisadores com diferentes graus acadêmicos - alunos de iniciação científica, mestrandos, mestres, doutorandos e doutores - e são reconhecidos pelas pesquisas que realizam pelos seus pares.

Vincennes foi criado no ano de 2005 por Charles, um engenheiro elétrico que se dedica a estudar biomecânica desde o seu mestrado, defendido em 1994. Em sua dissertação criou um eletromiógrafo - aparelho que mede a atividade elétrica dos músculos. Já no doutorado, implementou uma análise a partir da técnica da dinâmica inversa, que consistiu em um software para analisar as forças no tornozelo, joelho e quadril nos movimentos de caminhar, correr, saltar e agachar. Com o objetivo de continuar suas pesquisas, Charles, que já era professor no curso de EF e no PPG, reuniu seus alunos orientandos de iniciação científica e pós-graduação e iniciou o Vincennes.

Já, o grupo Buttes-Chaumont foi criado em 1997 por Olivier, após o término do seu doutorado, realizado na Espanha, sobre os temas cultura docente, EF e escolas públicas. Naquele ano, ao retornar às suas atividades na universidade, após o afastamento para a realização do seu doutorado, Olivier tinha a preocupação de concretizar um dos apontamentos que fez nas "conclusões" de sua tese de doutorado: "juntar os professores da escola com os professores da universidade" (entrevista com Olivier, 10.09.2014). A partir dessa constatação - que, conforme seu relato na entrevista, mescla tanto objetivos acadêmicos quanto políticos Olivier convidou professores da Rede Municipal de Ensino (RME) da cidade onde habita para participarem de reuniões de estudo e realizarem pesquisas sobre suas práticas docentes. Assim, ele criou "um grupo de investigação com professores da Rede e professores da universidade" (entrevista com Olivier, 10.09.2014) que, no início, tinha cerca de cinco integrantes. Nesse mesmo período, ele se vinculou ao PPG da Escola de EF e orientou sua primeira aluna de mestrado, que, à época, também era professora da RME.

Passados nove e 17 anos da criação desses grupos, atualmente, ambos são formados por cerca de 30 pesquisadores que desenvolvem pesquisas vinculadas aos propósitos iniciais de cada grupo. No Vincennes o foco é mecânica do movimento humano, mais especificamente

9 Para sustentar essas afirmações apresentamos no próximo tópico alguns dados empíricos que foram construídos ao longo da etnografia. Para acessar outras informações e descrições aprofundadas ver SILVEIRA, 2016. 
questões que envolvem forças. Diferentes práticas físicas e distintas partes do corpo humano são analisadas pelos pesquisadores com o intuito de medir forças musculares, propulsivas, internas e de resistência. Exercícios de Pilates, natação e balé, as regiões do ombro, joelho e coluna vertebral são os objetos das investigações realizadas pelo Vincennes. Já no ButtesChaumont, o foco é compreender questões que envolvem o professorado de EF de escolas. Tendo como locus a rede municipal de ensino, as pesquisas visam compreender a formação permanente e a prática pedagógica de professores, os conteúdos escolares da EF, a política pública de formação de professores, a organização curricular das escolas municipais, os sentidos da escola e da EF na atualidade, as questões raciais presentes nas escolas, 0 desgaste e o processo de abandono da carreira docente.

No que se refere aos aspectos teórico-metodológicos que pautam suas pesquisas, no Vincennes os fatos estudados devem resultar de um conjunto de ações que constituem um protocolo de pesquisa que abrange desde a escolha das variáveis ${ }^{10}$ a serem estudadas até a análise estatística. Nesse percurso, todos os testes realizados e equipamentos utilizados devem, em última instância, implicar informações quantificáveis, pois só serão adjetivadas de "científicas" após passarem pelo crivo da estatística. Durante o período de observações, inúmeras foram as vezes em que a resposta de Charles para propostas de temas e problemas de pesquisa trazidos pelos pesquisadores girava em torno da pergunta: "Como vamos medir?". Essa questão, apesar de parecer simples em um primeiro momento, desencadeava outras perguntas que, pouco a pouco, delimitavam as possibilidades do que era possível ser investigado: o que medir? Por que medir A e não B? Quem vai ser medido? Quantos serão medidos? O que sugere a literatura? Que testes serão utilizados para medir? Por que esses testes e não outros? Eles estão de acordo com as exigências do Comitê de Ética? Quem sabe realizar esses testes? Que materiais e equipamentos são necessários? Há no laboratório? E se não há, como consegui-los? Que software será utilizado para processar os sinais? Quem sabe operar o software? Que tipo de tabela e gráfico construir com os números obtidos? Que testes estatísticos utilizar? Por quê? O que significa ser ou não estatisticamente significativo?

A partir dessas questões os pesquisadores iniciam o processo de definição acerca de como a pesquisa será realizada. Com diversas possibilidades de ação, suas escolhas são feitas a partir de critérios que envolvem diferentes tipos de aliados ${ }^{11}$ que são associados ao processo da pesquisa para que esta seja cada vez mais legítima. Um dos primeiros passos é determinar quais serão as variáveis e as características das pessoas que serão avaliadas nas investigações, pois é a partir dessas decisões que serão escolhidos os métodos a serem utilizados. É com base nos objetivos geral e específicos das pesquisas realizadas no Vincennes que as decisões sobre as variáveis e o chamado grupo amostral são tomadas, utilizando diferentes tipos de critérios: outras pesquisas já publicadas sobre o mesmo tema; condições materiais para mensurar as variáveis escolhidas; condições de obter a amostra escolhida; recursos financeiros e os aspectos éticos envolvidos. Durante o processo de definição, contudo, muitas vezes não há consenso, pois os critérios utilizados apresentam divergências. Nesses casos, a decisão sobre qual critério prevalecerá sobre os demais é consequência de discussões entre os pesquisadores e resulta na elaboração de justificativas que devem ser sustentadas pela literatura ou por alguma instituição reconhecida entre os pares.

\footnotetext{
10 A expressão "variável" está presente em todas as pesquisas do grupo e refere-se à informação que, observada em um experimento, pode variar de um indivíduo para o outro.

11 O termo "aliados" faz referência aos diferentes tipos de elementos (humanos e não humanos) que são unidos e/ou se unem para sustentar determinadas ações e legitimá-las. Latour considera que o "recrutamento de aliados" (LATOUR, 2000, p. 196) é um processo importante não somente para "fechar uma caixa-preta" como também para manter a controvérsia estabilizada.
} 
De maneira distinta, ao acompanharmos o cotidiano do Buttes-Chaumont, nos ficou evidente que para ser pesquisador tem que ser professor, ou, ao menos, ter sido professor, uma vez que os fatos que se tornavam interessantes de serem investigados estavam atrelados a situações, vivências e acontecimentos oriundos das quadras escolares, das salas de aula, das propostas curriculares, das salas dos professores, dos projetos políticos pedagógicos e da Lei de Diretrizes e Bases da Educação. Inúmeras vezes, em conversas informais mantidas com pesquisadores do grupo, percebemos que os temas de suas pesquisas surgiram de vivências oriundas de suas experiências na escola. Os objetivos das pesquisas colocam em evidência a maneira com que as coisas acontecem na escola ou são significadas por quem as vive. As atenções se direcionam às características das pessoas que estão sendo investigadas, sejam elas professores e/ou estudantes; para as ações e os entendimentos que essas pessoas têm sobre a realidade que estão vivenciando; para as escolas em que estão inseridas; e também para os temas específicos que são pauta das investigações.

Para isso, o grupo se apropria de preceitos das metodologias qualitativas, demarcando distância das metodologias quantitativas e com os fazeres científicos historicamente mais reconhecidos na EF. As pesquisas são desenvolvidas a partir de etnografias, com associações de pesquisas vinculadas à Educação, dando visibilidade à agência dos sujeitos investigados. Os textos finais das pesquisas apresentam um caráter hermenêutico, característica que tem a potencialidade de distinguir "o que é" e "o que não é" um texto científico na ciência promulgada e produzida no grupo. Conforme palavras de Olivier, é necessário que o texto tenha uma qualidade "hermenêutica, que leva em conta as representações, que leva em conta os significados, que leva em conta as subjetividades" (Entrevista com Olivier, 16.09.2014). Qualquer que seja a dissertação, tese ou artigo produzido, precisa ser escrito com o entendimento de que, conforme ouvimos de Olivier inúmeras vezes durante o período do trabalho de campo, "este é um texto para o universo acadêmico".

Essa frase de Olivier foi proferida em quase todas as vezes em que ele se referia a alguma tese ou dissertação que estava sendo escrita. Para ele, o texto "para o universo acadêmico" difere de outros textos, pois demonstra todos os rigores metodológicos da pesquisa e coloca em diálogo as informações elaboradas no trabalho de campo, os referenciais teóricos e as interpretações do próprio pesquisador. Essa última característica é fundamental para Olivier e, consequentemente, para a ciência vivenciada no grupo, pois é a partir desse diálogo que se elaboram os resultados das pesquisas. Percebemos, ao longo do trabalho de campo, que essa importância, ênfase e demarcação na forma de escrita dos textos finais das pesquisas estão relacionadas a dois formatos de escrita distintos daqueles produzidos para o "universo acadêmico": o "romance" e o "discurso de palanque"12. Para Olivier, os textos científicos não podem ser apenas descritivos, o que os caracterizaria um romance, em termos de estilo literário; e também não podem ser apenas opiniões, o que os transformaria em um "discurso político-ideológico". A primeira distinção faz referência aos trabalhos acadêmicos que priorizam a apresentação das informações obtidas ao longo da pesquisa empírica e não realizam interpretações sobre essas informações. Em relação à segunda distinção, percebemos que Olivier está se referindo a uma característica que o grupo tem de ter integrantes politicamente engajados e/ou com trajetórias dentro do Movimento Estudantil da EF, em que há uma militância frente a diversos temas a partir do marxismo.

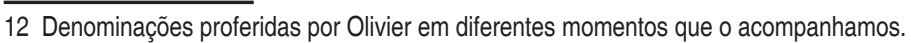


Com essas distintas maneiras de fazer ciências, Vincennes e Buttes-Chaumont vivenciam diferentemente o processo de pleito de fomento e avaliação de pesquisas e pesquisadores(as). Vincennes e Buttes-Chaumont, por estarem vinculados à Área 21, concorrem aos mesmos editais de fomento dentro da área e, por integrarem o mesmo PPG em $E F$, compartilham das mesmas exigências em termos de produção científica. A pontuação que seus(uas) pesquisadores(as) precisam fazer para ingressarem ou se manterem no PPG, por exemplo, é a mesma. Para que os(as) pesquisadores(as) do Vincennes alcancem a quantidade/ qualidade de publicações necessárias para serem contemplados(as) com algum fomento, aquilo que é exigido pelos processos avaliativos dos quais participam nunca pareceu ser um problema: inúmeras vezes Charles mencionou que jamais precisou "contar os pontos" de suas publicações frente aos critérios estabelecidos pela Capes, pois atingia a pontuação mínima exigida para se manter na condição de docente do PPG com facilidade. Ele também relatou que o seu currículo nunca foi apontado como insuficiente/insatisfatório pelos pareceres de editais de fomento a que concorreu. Já em relação aos demais pesquisadores(as), em sua quase totalidade alunos(as) do PPG, suas publicações também sempre foram ao menos suficientes para que conseguissem ser contemplados nos editais de bolsas de estudos. $O$ fato de que das pesquisas que realizam derivam diversas publicações e também a particularidade de que a redação de algumas teses e dissertações pode ser desenvolvida no formato de artigos fazem com que os(as) pesquisadores(as) do grupo não se preocupem com as publicações científicas, pois já estão estabelecidas estratégias para que isso aconteça de forma continuada. Para eles(as), a produção científica em periódicos nos estratos superiores do Qualis e com alto Fator de Impacto é o meio mais legítimo de reconhecimento de que suas pesquisas têm qualidade e atingem o objetivo de colaborar para a compreensão das temáticas que investigam.

De maneira diferente, para os pesquisadores do Buttes-Chaumont, o meio legítimo de reconhecimento de suas pesquisas não está relacionado diretamente a um aumento de publicações e o direcionamento dessas para periódicos bem classificados segundo os critérios estipulados pela Capes (a partir do Qualis) ou pela Thomson Reuters (a partir do Fator de Impacto). Apesar desses aspectos não serem descartados, porque esses pesquisadores atentam para os Qualis dos periódicos que escolhem publicar seus estudos, eles almejam outras implicações com suas pesquisas.

Um exemplo pode ser constatado no caso de Simone ${ }^{13}$ e os desejos, os interesses e os anseios que ela tinha em relação a sua pesquisa. Esses interesses não envolviam apenas publicações científicas. Para Simone, ter um artigo em uma revista científica não era exclusivamente um indicador capaz de avaliar sua pesquisa; para ela, o que the informaria de maneira mais eficiente se sua pesquisa havia alcançado o reconhecimento esperado seriam os usos que os professores de EF Escolar pudessem fazer com os resultados estabelecidos no final do seu processo de investigação. Nessa direção, Simone desenvolveu, além de uma dissertação escrita, uma dissertação em formato de CD com músicas que materializam seu trabalho. Para essa pesquisadora, era fundamental que os resultados da sua pesquisa fossem acessados pelos professores da RME que ela se dedicou a investigar. A escolha em desenvolver um CD que expressasse os resultados que ela elaborou está relacionada ao lugar aonde ela pretendia chegar, pois, conforme palavras de Simone, "[...] os professores da rede serão alcançados com a minha pesquisa e poderão, a partir das músicas, trabalhar com as questões étnico-raciais em suas aulas. É isso que eu quero fazer" (Diário de campo, 9 de maio de 2014). 
Em suma, ao acompanhar as rotinas dos grupos Buttes-Chaumont e Vincennes foi possível identificar que os elementos e associações que mantêm sua existência e seu reconhecimento na comunidade científica em que estão inseridos são diferentes. Compreendemos que os fazeres científicos da EF vão sendo feitos, produzidos e vivenciados, e, assim, novas realidades estão sendo promulgadas. Ao longo da pesquisa etnográfica e da aproximação com os ESCT construímos a compreensão de que existem e coexistem muitas outras ciências da EF além das duas que acompanhamos nesta pesquisa. Umas com mais proximidade do que outras, com mais conexões do que outras, com mais entrelaçamentos do que outras. Enfim, existem múltiplas ciências da EF. Essa constatação nos provoca a pensar nas implicações dessa multiplicidade, as quais envolvem negociações em diferentes esferas entre essas ciências, resultando muitas vezes em acordos, regras e políticas que favorecem umas em detrimento de outras.

\section{CONSIDERAÇÕES FINAIS}

Retomando a pergunta que conduziu a realização desta pesquisa anunciada no final da Introdução, fomos conduzidos, ao ver/sentir as diferenças entre a ciência feita no Vincennes e aquela feita no Buttes-Chaumont, a multiplicar as realidades científicas da EF. Passamos a compreender que tanto as ciências vivenciadas e produzidas nesses grupos quanto as promulgadas por outros coletivos constituem distintos fazeres que passam a se relacionar em alguns espaços/tempos. A ciência da EF tornou-se múltipla. E a sua forma no singular passou a ser compreendida a partir da coexistência de múltiplas ciências. Ou seja, o entendimento que passamos a assumir é de que não há uma ciência da EF (ou um campo científico da EF) que tenha a característica de estar dividida em áreas/subáreas, mas, sim, múltiplas ciências da EF sendo vivenciadas e que, em alguns espaços/tempos, através de vários tipos de relações, coexistem para se tornarem uma. Diversas são as maneiras com que essas múltiplas ciências, na prática, coexistem e tornam-se uma ciência da EF: em entidades científicas, em PPGs, em editais diversos de fomento à pesquisa e em diversos âmbitos de intervenção ${ }^{14}$.

Em diálogo com os estudos sobre ciência e EF, em que ficam evidentes as tensões, desigualdades e outras implicações que compõem o cotidiano científico da EF, chamamos atenção neste artigo para a coexistência das ciências da EF promulgadas por Vincennes e ButtesChaumont quando essas submetem-se aos diversos processos avaliativos para pleitearem notas ao PPG que estão vinculadas ou fomentos para suas pesquisas e pesquisadores. As agências de fomento e avaliação, ao utilizarem a produção científica como meio legítimo de classificar PPGs, pesquisas e pesquisadores, favorecem, nesses processos, as ciências da EF que têm em seus fazeres esse mesmo indicador para avaliar as pesquisas que fazem. $A$ ciência promulgada pelo grupo Vincennes é um exemplo dessas ciências, as quais, nesses processos, estão sendo beneficiadas. Fato esse que não acontece com o grupo ButtesChaumont. Assim, parece estar evidente que as agências de fomento e avaliação induzem que os resultados dos fazeres científicos sejam os mesmos para diferentes realidades: a produção científica. Além disso, fazem com que as ciências que não estão em convergência com esse indicador sejam prejudicadas nesses processos. Uma das consequências, por exemplo, é o descredenciamento de muitos pesquisadores dos PPG, conforme a situação prevista por Bruno (docente da universidade, pesquisador e vice-coordenador do Buttes-Chaumont) em relação

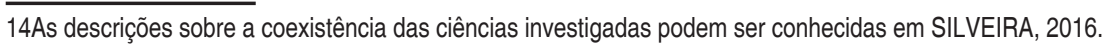


a sua permanência ou não no programa em que atua. Parece ser evidente, ao acompanhar as rotinas do Vincennes e do Buttes-Chaumont, que ter a produção científica como o meio de coordenar as diferentes ciências que promulgam para torná-las comparáveis e poder classificá-las gera desigualdades nos processos de fomento e avaliação dos quais participam, colaborando para a manutenção e a criação das discrepâncias que há entre essas múltiplas ciências.

Enfim, a partir da interlocução estabelecida com os ESCT, do processo etnográfico e dos entendimentos que assumimos frente às ciências, compreender as ciências da EF enquanto múltiplas abre possibilidades de estabelecermos um caminho analítico e, quiçá empírico, diferentemente do que até agora tem sido usado para o entendimento da temática.

\section{REFERÊNCIAS}

FONSECA, Claudia. O anonimato e o texto antropológico: dilemas éticos e políticos da etnografia 'em casa'. Teoria e Cultura, v. 2, n. 1/2, p. 39-53, jan./dez., 2008.

HAYASHI, Maria Cristina Piumbato Innocentini et al. Sociologia da ciência: primeiras aproximações ao campo. Revista Tecnologia e Sociedade, v. 2, p. 72-85, 2010.

LATOUR, Bruno. A esperança de pandora: ensaios sobre a realidade dos estudos científicos. Bauru, SP: EDUSC, 2001.

LATOUR, Bruno. Ciência em Ação: como seguir cientistas e engenheiros sociedade afora. Tradução Ivone C. Benedetti; revisão de tradução Jesus de Paula Assis. São Paulo: Editora Unesp, 2000.

LAW, John. Notes on the theory of the actor-network: Ordering, strategy, and heterogeneity. Systemic Practice and Action Research. v. 5, n. 4, p. 379-393, 1992.

LAZZAROTTI FILHO, Ari et al. Modus operandi da produção científica da Educação Física: uma análise das revistas e suas veiculações. Revista da Educação Física/UEM, v. 23, n. 1, p. 1-14, 1. trim., 2012.

LAZZAROTTI FILHO, Ari. O Modus Operandi do Campo Acadêmico-científico da Educação Física no Brasil. 2011. 147f. Tese (Doutorado) - Programa de Pós-Graduação em Educação Física, Universidade Federal de Santa Catarina, Florianópolis, 2011.

MANOEL, Edson de Jesus; CARVALHO, Yara Maria de Carvalho. Pós-Graduação na Educação Física Brasileira: A atração (fatal) para a biodinâmica. Educação e Pesquisa, v. 37, n. 2, p. 389406, maio/ago. 2011.

MARCHLEWSKI, Camila; SILVA, Priscilla Maia da; SORIANO, Jean Barcelos. A influência do sistema de avaliação Qualis na produção de conhecimento científico: algumas reflexões sobre a Educação Física. Motriz, v. 17, n. 1, p. 104-116, jan./mar. 2011.

MOL, Annemarie. Política ontológica: algumas ideias e várias perguntas. In: NUNES, João Arriscado; ROQUE, Ricardo. Objectos impuros: experiências em estudos sociais da ciência. Tradução de Gonçalo Praça. Porto: Edições Afrontamento, 2008. p.63-75. 
MOL, Annemarie. The body multiple: ontology in medical practice. Durham: Duke University, 2002.

RECHIA, Simone et al. Dilemas e desafios da Pós-Graduação em Educação Física. ljuí: Editora Unijuí, 2015.

RIGO, Luis Carlos; RIBEIRO, Gabriela M.; HALLAL, Pedro C. Unidade na diversidade: desafios para a Educação Física no século XXI. Revista Brasileira de Atividade Física \& Saúde, v. 16, n. 4, p. 339-345, 2011.

SILVA, Rossana Valéria de Souza e. Pesquisa em Educação Física: determinações históricas e implicações epistemológicas. 1997. 279f. Tese (Doutorado) - Faculdade de Educação, Universidade de Campinas, Campinas, 1997.

SILVEIRA, Raquel. Vivendo Ciências: As (co)existências de diferentes ontologias científicas da Educação Física. 2016. 431f. Tese (Doutorado) - Escola de Educação Física, Programa de PósGraduação em Ciências do Movimento Humano, Porto Alegre, 2016.

STIGGER, Marco Paulo et al. Revista Movimento: análise dos sentidos e da repercussão de um periódico que "se faz" no campo da Educação Física brasileira. Movimento, v. 16, n. esp., p. 113-154, 2010.

STIGGER, Marco Paulo. Apresentação. In: STIGGER, Marco Paulo (org.). Educação Física + Humanas. Campinas, SP: Autores Associados, 2015, p. VII-X.

STIGGER, Marco Paulo; SILVEIRA, Raquel da; MYSKIW, Mauro. O processo de avaliação da pós-graduação em Educação Física e Ciências do Esporte no Brasil e algumas das suas repercussões cotidianas. In: RECHIA, Simone et al. Dilemas e desafios da Pós-Graduação em Educação Física. ljuí: Editora Unijuí, 2015. p. 15-56.

TAVARES, Otávio. Desafios e dilemas da pós-graduação em Educação Física: os Estudos Socioculturais e a Área 21. In: RECHIA, Simone et al. Dilemas e desafios da Pós-Graduação em Educação Física. ljuí: Editora Unijuí, 2015. p. 219-234.

Apoio:

CNPQ. 